\title{
Evolutionary aspects of elemental hyperaccumulation
}

\author{
Jennifer J. Cappa $\cdot$ Elizabeth A. H. Pilon-Smits
}

Received: 29 August 2013 / Accepted: 14 October 2013 / Published online: 24 October 2013

(C) Springer-Verlag Berlin Heidelberg 2013

\begin{abstract}
Hyperaccumulation is the uptake of one or more metal/metalloids to concentrations greater than 50-100x those of the surrounding vegetation or $100-10,000 \mathrm{mg} / \mathrm{kg}$ dry weight depending on the element. Hyperaccumulation has been documented in at least 515 taxa of angiosperms. By mapping the occurrence of hyperaccumulators onto the angiosperm phylogeny, we show hyperaccumulation has had multiple origins across the angiosperms. Even within a given order, family or genus, there are typically multiple origins of hyperaccumulation, either for the same or different elements. We address which selective pressures may have led to the evolution of hyperaccumulation and whether there is evidence for co-evolution with ecological partners. Considerable evidence supports the elementaldefense hypothesis, which states that hyperaccumulated elements protect the plants from herbivores and pathogens. There is also evidence that hyperaccumulation can result in drought stress protection, allelopathic effects or physiological benefits. In many instances, ecological partners of hyperaccumulators have evolved resistance to the hyperaccumulated element, indicating co-evolution. Studies on the molecular evolution of hyperaccumulation have pinpointed gene duplication as a common cause of increased metal transporter abundance. Hypertolerance to the hyperaccumulated element often relies upon chelating agents, such as organic acids (e.g., malate, citrate) or peptide/protein chelators that can facilitate transport and sequestration. We
\end{abstract}

Electronic supplementary material The online version of this article (doi:10.1007/s00425-013-1983-0) contains supplementary material, which is available to authorized users.

J. J. Cappa · E. A. H. Pilon-Smits $(\bowtie)$

Department of Biology, Colorado State University,

Fort Collins, CO 80523-1878, USA

e-mail: epsmits@1amar.colostate.edu conclude the review with a summary and suggested future directions for hyperaccumulator research.

\section{Introduction}

Over five hundred species of plants have been documented to hyperaccumulate one or more trace metal/metalloids, including arsenic (As), cadmium (Cd), chromium $(\mathrm{Cr})$, cobalt $(\mathrm{Co})$, copper $(\mathrm{Cu})$, lead $(\mathrm{Pb})$, manganese $(\mathrm{Mn})$, nickel (Ni), selenium (Se) and zinc ( $\mathrm{Zn})$. Most hyperaccumulators are flowering plants, but a few fern species have been documented to hyperaccumulate As (Reeves and Baker 2000; Ma et al. 2001). In this review, we focus on angiosperm hyperaccumulators.

Plant hyperaccumulators are defined as having $50-100 \times$ higher concentrations of the element relative to that of the surrounding vegetation, or equivalent to $100-10,000 \mathrm{mg} / \mathrm{kg}$ dry weight (DW; Maestri et al. 2010; for a recent review on hyperaccumulation see also Van der Ent et al. 2013). Hyperaccumulators are predominantly found on soils that contain elevated levels of the hyperaccumulated element, which suggests that they have evolved in situ on these soils. Importantly, these soils are not just naturally occurring soils, but also anthropogenically contaminated soil, which may indicate that hyperaccumulation can evolve rapidly. Alternatively, the hyperaccumulators may just have colonized the mine tailings from an original outcropping of surface-facing ore. Given the immobility of plants it is understandable that taxa inhabiting soils with high levels of toxic elements have evolved tolerance mechanisms. Indeed, hyperaccumulators are tolerant to the extreme soils they grow on. However, it is intriguing that hyperaccumulators appear to actively concentrate the toxic element(s). Hyperaccumulation is not necessary for survival on soils 
with elevated levels of the element, but rather requires extra evolutionary steps for hypertolerance to the high levels of the toxic metal/metalloid in their tissues. This review will address the following four evolutionary questions. First, how many times did hyperaccumulation evolve? Second, what selection pressures have driven the evolution of hyperaccumulation? Third, is there co-evolution with the ecological partners of hyperaccumulating plants? Fourth, what do we know about the molecular evolution of hyperaccumulation?

\section{How many times did hyperaccumulation evolve?}

To understand the evolutionary basis of hyperaccumulation we need to know how hyperaccumulation is distributed across the angiosperms. There have been reports of over 500 hyperaccumulators among the 250,000 angiosperm species (Stevens 2001 onwards), equating to $\sim 0.2 \%$ of species (Suppl. Table 1). The majority of these 500 species are $\mathrm{Ni}$ hyperaccumulators. At the genus level, $181 / 13,000$ genera $=1.4 \%$ hyperaccumulate and 60/443 families $=13.5 \%$ contain hyperaccumulators. The following angiosperm families contain an unusually high percentage of the total hyperaccumulating taxa (Fig. 1): Brassicaceae, Euphorbiaceae and Asteraceae. Hyperaccumulation, even of a single element, appears to have evolved several times within vascular plants: it is distributed widely across the phylogeny. At multiple taxonomic levels (order, family, genus), we find several origins of hyperaccumulation. For instance, Krämer (2010) proposes that within the Brassicaceae there are at least six independent origins of $\mathrm{Ni}$ hyperaccumulation, three origins of $\mathrm{Zn}$ and $\mathrm{Cd}$ hyperaccumulation, two origins of As hyperaccumulation and one origin of Se hyperaccumulation. Alyssum (Brassicaceae) contains upward of 50 nickel hyperaccumulating species without an obvious pattern of origin either at the phylogenetic or geographic level (Cecchi et al. 2010). Given the high number of hyperaccumulating taxa and the general lack of phylogenetic or geographic correlation of Ni hyperaccumulators, there may be a predisposition within the Alysseae to adapt to serpentine soils high in Ni.

Natural variation within species

Probably, the two most studied hyperaccumulator species are Arabidopsis halleri and Noccaea caerulescens (formerly, Thlaspi caerulescens) (both in the Brassicaceae) which hyperaccumulate $\mathrm{Zn}$ and $\mathrm{Cd}$, and $\mathrm{Zn}, \mathrm{Ni}$ and $\mathrm{Cd}$, respectively. There is evidence that $\mathrm{Zn}$ hyperaccumulation is a constitutive trait in A. halleri, but that Cd hyperaccumulation is variable (Bert et al. 2002). A parallel situation exists in $N$. caerulescens (Lombi et al. 2000). Besnard et al. (2009) conducted a population genetic study on $N$. caerulescens using nuclear and plastid loci across multiple accessions from Switzerland. They found strong population structure (based on neutral markers) that was not associated with $\mathrm{Cd}$ or $\mathrm{Zn}$ levels in the soil. However, allelic richness of candidate loci, particularly metal transporters, was positively correlated with metal concentrations in the soil. In addition to variation in Cd uptake in $N$. caerulescens, there is evidence for competition between the various metals ( $\mathrm{Cd}$, Ni and $\mathrm{Zn}$ ), with $\mathrm{Cd}$ and $\mathrm{Zn}$ taken up in higher concentrations when competing with $\mathrm{Ni}-$ even from $\mathrm{Ni}$ hyperaccumulating populations (Assunção et al. 2008). In addition, $N$. goesingense populations were shown to accumulate high concentrations of $\mathrm{Ni}, \mathrm{Zn}, \mathrm{Mn}$ and Co regardless of whether the populations came from serpentine or non-serpentine soils (Reeves and Baker 1984).

In contrast to hyperaccumulation being a constitutive trait, some species show strong ecotypic variation. Populations of Stanleya pinnata have been shown to vary in Se concentration depending on the population tested; these differences appear to be fixed based on common garden experiments (Feist and Parker 2001). Substantial population-level variation was also found for $\mathrm{Ni}$ accumulation in the $\mathrm{Ni}$ hyperaccumulator Alyssum bertolonii (Galardi et al. 2007). The Cd hyperaccumulator Sedum alfredii also has fixed ecotypic differences including differences in $\mathrm{Cd}$ sequestration (Tian et al. 2011) and translocation (Lu et al. 2008).

Phylogenetic conclusions

In conclusion, hyperaccumulation is broadly distributed over the plant phylogeny and must have evolved independently many times. Even within a family or genus there is rarely unequivocal evidence for one origin of hyperaccumulation when more than one species is a hyperaccumulator. If we take an even closer look at the species level, populations differ in their ability to accumulate and tolerate certain elements, and within a population individuals commonly differ in their tolerance and accumulation and these differences can be dependent on the element accumulated, e.g., $\mathrm{Zn}$ vs. Cd. Thus, hyperaccumulation is a constantly evolving trait and under selection.

\section{Which selection pressures favored the evolution of hyperaccumulation?}

Several hypotheses have been proposed for the functional significance of metal and metalloid hyperaccumulation by plants (Boyd and Martens 1992). There is considerable evidence that accumulation of toxic elements can offer plants protection from herbivores and pathogens, which is 
\# taxa (\# families)

Element(s)

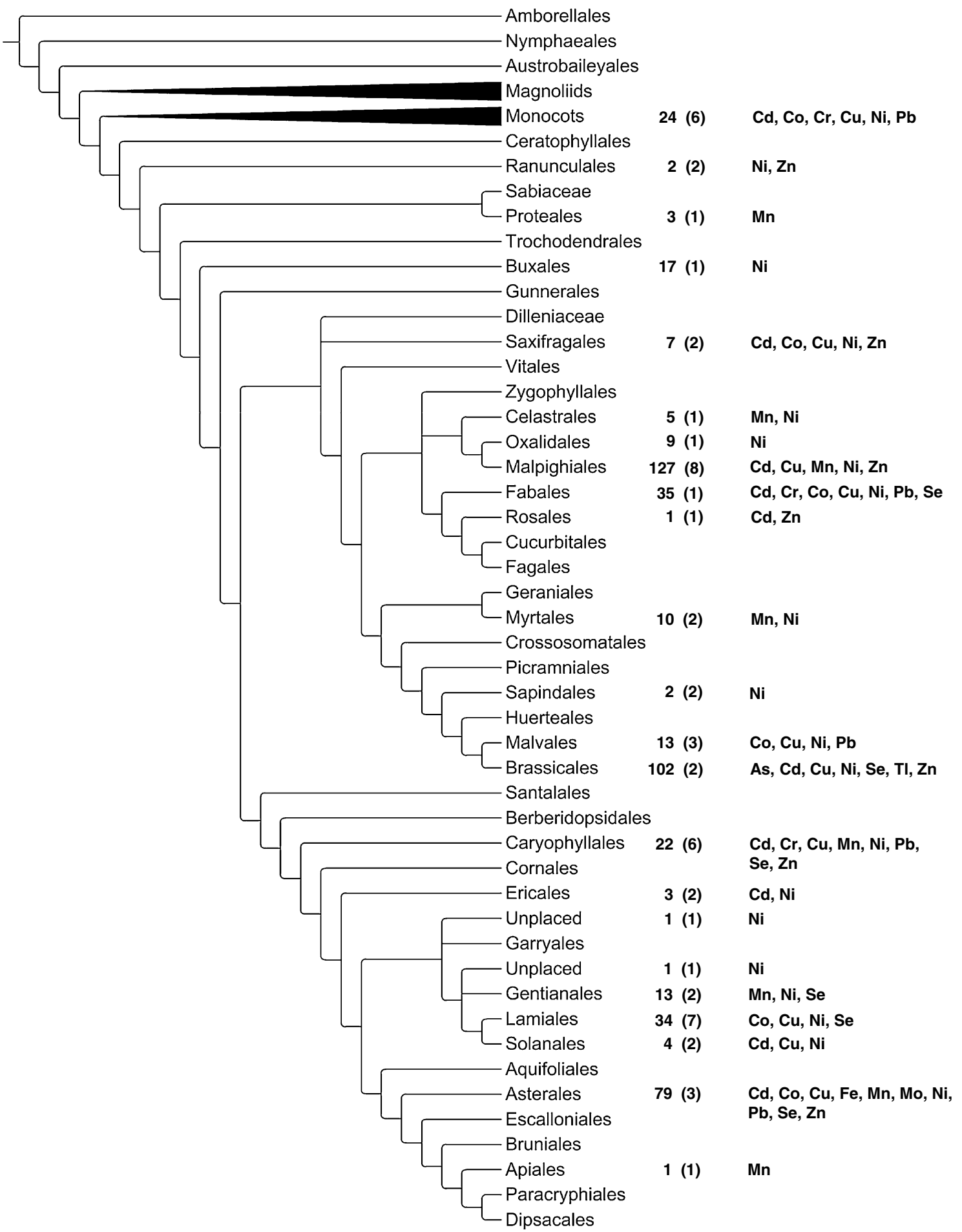

Fig. 1 Occurrence of elemental hyperaccumulation in angiosperms. Phylogenetic tree modified from angiosperm phylogeny group (APG) III (Stevens 2001). For more detailed information about which taxa hyperaccumulate each element, see Supplemental Table 1

in agreement with the elemental-defense hypothesis (Boyd and Martens 1992). The protective effect against herbivores includes both deterrence and toxicity. High levels of $\mathrm{Ni}$ in plants have been shown to protect them from a variety of herbivores and pathogens (Boyd et al. 1994; Boyd and Moar 1999; Martens and Boyd 2002). Zinc and Cd can 
also protect plants from invertebrate herbivory (Pollard and Bakers 1997; Jhee et al. 1999). Similarly, Se can protect plants from a variety of herbivores and pathogens, including moth and butterfly larvae, aphids, thrips, spider mites, grasshoppers, prairie dogs, as well as fungal pathogens (Vickerman and Trumble 1999; Hanson et al. 2004; Freeman et al. 2006b, 2007, 2009; Quinn et al. 2008, 2010a, b). Arsenic has also been shown to protect plants from herbivores (Mathews et al. 2009). In further support of a defensive role, it appears that the hyperaccumulated element is often concentrated in organs and tissues that are most susceptible to herbivores and pathogens (Freeman et al. 2006b; Tappero 2008). The levels at which elements become protective against herbivores or pathogens depend on the element and chemical form the plant accumulates, as well as the sensitivity of the herbivore or pathogen in question. For example, Se in plants is effective against aphids below $10 \mathrm{mg} \mathrm{kg}^{-1}$ DW (Hanson et al. 2004), whereas plants needed an order of magnitude more Se to be protected from Lepidoptera larvae or prairie dogs, and even higher levels to be protected from spider mites (Freeman et al. 2006b, 2009; Quinn et al. 2010a, b). Different elements may also show synergistic interactions in vivo with each other and with organic defense compounds, reducing the level at which they become effective. This phenomenon has been termed the joint-effects hypothesis by Boyd (2012). These examples provide strong evidence that herbivores and pathogens can act as selection pressure for the evolution of increasing elemental accumulation in plants. This selection pressure can be effective at tissue elemental concentrations well below hyperaccumulator level and is expected to be incremental: the higher the elemental tissue concentration, the more effective and the broader is the protection from a range of pests.

There is also some evidence that hyperaccumulators benefit from their accumulated element via allelopathy, i.e., negative effects on neighboring plants, in support of another hypothesis put forward by Boyd and Martens (1992). Soil around Se hyperaccumulators Astragalus bisulcatus and Stanleya pinnata was found to be significantly enriched with $\mathrm{Se}$, and this soil significantly reduced germination and growth of the Se-sensitive plant species Arabidopsis thaliana and enhanced its Se levels compared to soil collected from non-hyperaccumulators (El Mehdawi et al. 2011a). No clear allelopathic effects were found for the Ni hyperaccumulator Alyssum murale (Zhang et al. 2007). While Ni-amended soil reduced seed germination of eight herbaceous species, leaf litter from A. murale did not, perhaps due to low $\mathrm{Ni}$ phytoavailability in leaf litter. More studies are needed, but it appears that for some hyperaccumulators allelopathic benefits may have contributed to the evolution of hyperaccumulation.
A third hypothesis as to why plants hyperaccumulate is protection from drought resistance (Boyd and Martens 1992). Whiting et al. (2003) found no evidence that $\mathrm{Ni}$ or $\mathrm{Zn}$ can protect plants from polyethylene glycol (PEG)induced osmotic stress. On the other hand, Bhatia et al. (2005) reported that Ni may play a role in osmotic adjustment in the hyperaccumulator Stackhousia tryonii, thereby protecting it from drought stress. While not a hyperaccumulator, it is interesting to note that Yao et al. (2012) found that Se treatment improved recovery of wheat seedlings from drought stress. Since the Se levels are low in this species, the mechanism may involve induction of some drought tolerance mechanism, rather than direct effect of the tissue Se on osmotic potential. In conclusion, there is evidence that hyperaccumulation may offer protection from drought stress in some species, but there is not as much evidence for protection from drought as protection from biotic stresses.

In some cases, enhanced accumulation of elements may have a positive physiological effect. This may be true for both essential and non-essential elements. For instance, the hyperaccumulator Noccaea caerulescens had a $75 \%$ increase in biomass when supplied with $\mathrm{Cd}$ after 31 days (Roosens et al. 2003). The element Se is not known to be essential for plants, but is beneficial for the growth of many plant species, especially Se hyperaccumulators (Virupaksha and Shrift 1965; El Mehdawi et al. 2012).

It is also possible that hyperaccumulation resulted from inadvertent uptake if the accumulated elements are chemically similar to essential nutrients and plant populations evolve more efficient uptake and translocation systems for these nutrients. For instance, Boyd and Martens (1998) suggested that $\mathrm{Ni}$ hyperaccumulation in N. montanum may be an inadvertent consequence of an efficient nutrient uptake system for another nutrient, perhaps for $\mathrm{Zn}$ or $\mathrm{Ca}$. Similarly, it is feasible that hyperaccumulation of $\mathrm{As}, \mathrm{Cd}$ and $\mathrm{Se}$ evolved as inadvertent side effects of enhanced phosphate, zinc/calcium and sulfate uptake, respectively.

Thus, several biotic and abiotic environmental factors as well as physiological processes may contribute to the evolution of elemental hyperaccumulation in a lineage. These various selection pressures may act simultaneously or individually, depending on the habitat, element and taxon.

\section{Is there co-evolution of hyperaccumulators with ecological partners?}

Plants have many ecological partners, including microbes, pollinators, herbivores and other plants. Elemental hyperaccumulation has been shown to negatively affect these partners if they are sensitive to the element in question, as described above. Thus, the hyperaccumulator may exert 
selection pressure on its ecological partners, leading to their partners having increasing resistance to the toxic element over time. Such resistant ecological partners can then exclusively occupy the new niches offered by hyperaccumulator plants. There is indeed evidence that ecological partners of hyperaccumulators have evolved resistance to the hyperaccumulated element. For example, Boyd (2009) reported insects that feed almost exclusively on $\mathrm{Ni}$ hyperaccumulators. He identified 15 insect species across three (sub)orders that can tolerate an internal $\mathrm{Ni}$ concentration of $\geq 500 \mathrm{mg} / \mathrm{kg}^{-1}$. A few of these species appeared to be specialists, since they chose to feed on a particular $\mathrm{Ni}$ hyperaccumulator even when given the choice of a different $\mathrm{Ni}$ hyperaccumulator or a non-hyperaccumulator. Similarly, several Se-resistant herbivorous moths, seed beetles and seed wasps were found to feed on Se hyperaccumulators A. bisulcatus and S. pinnata in their natural seleniferous habitat (Freeman et al. 2006b, 2012; ValdezBarillas et al. 2012). These situations appear to be classical examples of co-evolution, where plant and herbivore are in an "arms race", leading to ever increasing accumulation in the plant and resistance in the herbivore. There is also evidence of Se-tolerant microbial and micro-athropod detrivores in seleniferous ecosystems that efficiently decompose hyperaccumulator litter (Quinn et al. 2011a, b), as well as evidence of Se-tolerant endophytes and leaf pathogens that successfully occupy the niche provided by Se hyperaccumulators (Valdez-Barillas et al. 2012). Also, some Se-tolerant plant species were shown to benefit from close proximity to Se hyperaccumulators: they contained up to tenfold higher Se levels and enjoyed less herbivory and enhanced growth (El Mehdawi et al. 2011b). As a result of their negative effects on sensitive ecological partners and positive effects on resistant ecological partners, hyperaccumulators may affect species composition in the community at multiple trophic levels. Hyperaccumulators may also affect cycling of the hyperaccumulated element through their local ecosystem, by affecting its soil distribution and chemical form, and forming a portal for its entry into higher trophic levels (El Mehdawi and Pilon-Smits 2012).

\section{How did hyperaccumulation evolve, at the molecular level?}

Hyperaccumulators have evolved both enhanced capacity to sequester toxic elements and enhanced tolerance to these elements. The underlying mechanisms may be hypothesized to include mutations in transporter protein genes that enhance expression levels or change the kinetic properties of the transporter. Hyperaccumulators may be expected to have higher expression levels of various membrane transporters responsible for uptake into the root symplast, loading into the root xylem, uptake into the leaf symplast and sequestration into the vacuole and in specific tissues such as the epidermis. To facilitate transport of the toxic elements in xylem and phloem, hyperaccumulators may also be expected to have enhanced levels of chelating agents in either of these vascular tissues or in adjacent tissues. Such chelating agents may include organic acids (e.g., malate, citrate) or peptide/protein chelators (e.g., nicotianamine, glutathione, phytochelatins, histidine). Some of these same chelators may help the plants tolerate their extraordinarily high levels of these toxic elements. Hyperaccumulators may have enhanced levels of (other) antioxidant compounds and enzymes as additional tolerance mechanisms. In the case of Se, hyperaccumulators appear to have evolved mechanisms by which this element is converted to less toxic, organic forms (Neuhierl and Böck 1996).

From studies to date on different hyperaccumulator species, there appear to be several different cases by which hyperaccumulators have modified transporter abundance or activity. Some hyperaccumulators have increased the gene copy number of transporters via gene duplication events; examples include the HMA (heavy metal binding) transporter in A. halleri (Hanikenne et al. 2008) and N. caerulescens (Ueno et al. 2001; Craciun et al. 2012). In A. halleri, Hanikenne et al. (2008) sequenced bacterial artificial chromosomes and found three tandem copies of metal ATPase 4 (HMA4) relative to A. thaliana. In N. caerulescens, HMA4 was again shown to have a variable copy number in populations that differ in $\mathrm{Cd}$ accumulation and tolerance. The population with the least efficient $\mathrm{Cd}$ translocation had the lowest expression level and the lowest copy number (Craciun et al. 2012). There can be up to four tandem copies of HMA4 in N. caerulescens (Ó Lochlainn et al. 2011). In addition to HMA4, heavy metal ATPase 3 (HMA3) was implicated as conferring tolerance by being a tonoplastlocated transporter sequestering $\mathrm{Cd}$ into the leaf vacuoles. When higher and lower $\mathrm{Cd}$ accumulating ecotypes of $N$. caerulescens populations were compared, the authors found significantly higher $H M A 3$ expression in the more tolerant ecotype Ganges, which also had a greater number of gene copies (Ueno et al. 2001).

In hyperaccumulators of non-essential elements it appears that the hyperaccumulated element enters the plant via transporters for other, essential elements that are chemically similar to it. For instance, the non-essential elements $\mathrm{Se}, \mathrm{As}$ and $\mathrm{Cd}$ are chemically similar to $\mathrm{S}, \mathrm{P}$ and $\mathrm{Zn}$, respectively, and enter the plant through the transporters for these elements. Sulfate transporter (Sultr) 1;2 is apparently responsible for selenate import into the root in Arabidopsis thaliana, since lesions in sultrl;2 confer selenate resistance and increased tolerance in A. thaliana by reducing 
symplastic accumulation of Se (Shibagaki et al. 2002; Ohno et al. 2012). Several sulfate transporters were found to be more highly expressed in hyperaccumulator Astragalus spp. at levels comparable to those in non-hyperaccumulator plants present under S starvation (Cabannes et al. 2011). Similarly, several genes encoding sulfate transporters are constitutively upregulated in the $\mathrm{Se}$ hyperaccumulator $S$. pinnata relative to the non-hyperaccumulator $S$. albescens (Freeman et al. 2010). Thus, constitutive expression of sulfate transporters may be one of the mechanisms of Se hyperaccumulation. In addition, there is evidence of at least one Se-specific transporter in the hyperaccumulator $S$. pinnata: in contrast to non-hyperaccumulator species, selenate uptake in $S$. pinnata is not significantly inhibited by high sulfate levels (Harris and Pilon-Smits, unpublished results). Similarly, it has been shown that arsenate most likely is taken up via a phosphate transporter; for a review of arsenic uptake and metabolism in plants see Zhao et al. (2009).

The ZIP family (ZRT, IRT-like proteins) transporters are known to be involved in the movement of $\mathrm{Fe}, \mathrm{Zn}$, $\mathrm{Mn}$ and $\mathrm{Cd}$, with 15 paralogs identified in A. thaliana. In $\mathrm{Zn} / \mathrm{Cd}$ hyperaccumulators $A$. halleri and $N$. caerulescens, ZIP transporters have been shown to have a constitutively higher expression level relative to A. thaliana and Thlaspi arvense, respectively (Assunção et al. 2001; Becher et al. 2004; Weber et al. 2004). Furthermore, expression of two copies of the ZIP transporter gene IRT3, AtIRT3 and AhIRT3 were able to rescue a $\mathrm{Zn} / \mathrm{Fe}$ uptake-deficient Saccharomyces cerevisiae mutant (Lin et al. 2009). This work suggests that root transporters in the ZIP gene family are important factors in $\mathrm{Zn}$ hyperaccumulation. Beyond transporters, many metals/metalloids are complexed with chelators to allow for specific uptake, movement and sequestration within the different compartments of the plant body.

Many peptide/protein chelators have been implicated in providing a mechanism for (hyper)tolerance, including glutathione, histidine, nicotianamine and phytochelatins. Glutathione (GSH) may contribute to tolerance not only by binding toxic elements, but also by scavenging free radicals. Levels of GSH were found to be constitutively enhanced in Ni hyperaccumulator Noccaea goesingense (Freeman et al. 2004), as well as in Se hyperaccumulator Stanleya pinnata (Freeman et al. 2010). In Phytolacca americana, a Cd hyperaccumulator, the tissue concentration of GSH was shown to increase when supplied with $\mathrm{Cd}$ (Zhao et al. 2011). Histidine has been shown to be an important factor in Ni hyperaccumulators Alyssum lesbiacum (Krämer et al. 1996) and N. goesingense (Krämer et al. 2000). Histidine has also been shown to be important in root-to-shoot translocation in $N$. caerulescens by preventing the accumulation of histidine-bound $\mathrm{Ni}$ in the root vacuoles (Richau et al. 2009). Nicotianamine is present at elevated levels in the hyperaccumulator species, A. halleri and $N$. caerulescens relative to closely related non-hyperaccumulator species (Deinlein et al. 2012). Furthermore, in A. halleri an RNAi knockout of nicotianamine synthase resulted in decreased translocation of $\mathrm{Zn}$ from the root to and shoot, and the knockout plants did not reach hyperaccumulator levels of $\mathrm{Zn}$ in the shoots (Deinlein et al. 2012). Lastly, phytochelatin levels have been to shown to significantly increase in $P$. americana with increasing Cd supply, potentially to help sequester $\mathrm{Cd}$ ions in the leaf vacuoles (Gao et al. 2013). However, phytochelatin concentrations are typically lower in hyperaccumulator species than related non-hyperaccumulator species (Meyer et al. 2011) and therefore may not actually be an evolutionary mechanism in hyperaccumulator species. In addition to peptide/protein chelators, organic acids such as citrate and malate have also been implicated in tolerance and transport in hyperaccumulator species. It has been shown that citrate and malate bind to $\mathrm{Zn}$ and $\mathrm{Ni}$ to allow for loading and unloading into and out of xylem, phloem and across the tonoplast. In Sedum alfredii, Lu et al. (2013) showed increased levels of citrate in the xylem sap of plants from a hyperaccumulating population relative to a non-hyperaccumulating population and that the levels of citrate increased with increasing $\mathrm{Zn}$ concentration. Nickel hyperaccumulator Alyssum murale has increased citric acid and malic acid synthesis in the root mitochondria relative to non-hyperaccumulator A. montanum (Agrawal et al. 2013). In $N$. goesingense $\mathrm{Ni}$ has been shown to be bound to citrate (Krämer et al. 2000). In N. caerulescens $\mathrm{Zn}$ has been found to be stored chelated by malate and citrate in the vacuoles of epidermal cells. Elevated levels of these organic acids may help in $\mathrm{Zn}$ sequestration and tolerance of $\mathrm{Zn}$ in N. caerulescens (Schneider et al. 2013).

In addition to chelation, hyperaccumulators have in some cases evolved mechanisms by which elements are metabolized to less toxic forms. This is the case for Se. All plants can assimilate selenate to selenocysteine (SeCys) via the sulfate assimilation pathway. This SeCys may be non-specifically incorporated into protein, which is toxic. SeCys may also be further metabolized via selenocystathionine (SeCyst) to selenomethionine (SeMet) and other ana$\operatorname{logs}$ of reduced $\mathrm{S}$ compounds. Plants can also form volatile dimethylselenide (DMSe) from SeMet (Terry et al. 2000). A transcriptome study showed that in the hyperaccumulator Stanleya pinnata many genes from the $\mathrm{S}$ assimilation pathway were upregulated, as compared to non-hyperaccumulator S. albescens, perhaps due to higher levels of the plant-growth regulators, jasmonate, salicylate and ethylene (Freeman et al. 2010). This may explain the hyperaccumulator's higher levels of Se and S. The forms of Se in hyperaccumulators and non-hyperaccumulators are also different: while many non-hyperaccumulators accumulate predominantly selenate when treated with selenate, hyperaccumulators tend to accumulate organic Se. In 
S. pinnata, for instance, a large fraction of the Se is present as SeCyst (Shrift and Virupaksha 1965; Freeman et al. 2006b). These findings suggest that certain enzymes within the $S$ assimilation pathway may be differentially expressed in hyperaccumulators and non-hyperaccumulators. In addition, Se hyperaccumulators often contain methyl-SeCys, which is produced by an Se-specific SeCys methyltransferase (Neuhierl and Böck 1996; Sors et al. 2005; Freeman et al. 2006b). The accumulation of these non-protein amino acids, SeCyst and methyl-SeCys, prevent incorporation into protein, and thereby prevent toxicity to the plant (Brown and Shrift 1981; Neuhierl and Böck 1996). Hyperaccumulators may also volatilize Se at very high rates in the form of dimethyldiselenide (DMDSe), which is synthesized from methyl-SeCys (Freeman and Bañuelos 2011). Therefore, Se hyperaccumulators in the genera Stanleya and Astragalus appear to have evolved a unique pathway that plays an important role in their Se tolerance.

\section{Summary and future directions}

Many different hyperaccumulators have been studied and from these studies several mechanisms responsible for hyperaccumulation have been identified. Often, hyperaccumulators have enhanced levels of transporters (as a result of gene duplication) for uptake into the root and translocation within the plant. Hypertolerance mechanisms that have been identified include enhanced levels of chelators or of enzymes that convert the element to less toxic forms. Some interesting questions that may still be addressed include: Is there a "master switch" gene (e.g., some transcription factor) that upregulates all genes involved in hyperaccumulation and hypertolerance? Did hypertolerance evolve simultaneously with hyperaccumulation or did it evolve sequentially with hyperaccumulation? If the latter case is true, then which came first? Does one commonly precede the other, and is one trait more difficult to evolve?

Studies on elemental hyperaccumulation so far generally have used relatively few approaches: molecular, physiological, genetic or ecological. The next challenge will be to integrate these diverse approaches within a selected taxon. Such a comprehensive study may start with a complete documentation of the variation in tolerance and accumulation in a group of species/populations, in concert with phylogenetics/population genetics of the taxa of interest. This may be followed up by a comparative study of selected taxa to obtain insight into underlying biochemical and genetic mechanisms, hopefully leading to identification of candidate alleles that contribute to hyperaccumulation. In parallel, the ecological effects of hyperaccumulation may be studied within natural ecosystems to obtain insight into selection pressures. Finally, candidate alleles may be studied in natural systems for evidence of selection, and at the molecular level for evidence of positive selection.

The results from such studies have intrinsic scientific value. Adaptation to selective pressures on populations from biotic or abiotic factors is a key process to study in evolutionary biology, because it helps explain how interspecific differences arose. Rigorously studying local adaptation requires researchers to address questions at multiple organization levels of biology, because only by synthesizing information from disciplines such as molecular biology, cell biology, physiology, ecology and phylogenetics can we thoroughly document local adaptation by linking cellular responses to the relationships of species over time and correlate those with the ecological landscape. Hyperaccumulation offers a very promising model trait in this respect.

Beyond basic scientific value, results from such studies also may have broad applications in biofortification and phytoremediation. Identification of hyperaccumulation mechanisms and specific alleles allows for development of plants with enhanced tolerance to, and accumulation of, both nutrients and environmental pollutants.

Acknowledgments We thank Mark P. Simmons for critical reading of the manuscript and helpful discussion. We also thank the two anonymous reviewers for their helpful comments.

\section{References}

Agrawal B, Czymmek KJ, Sparks DL, Bais HP (2013) Transient influx of nickel in root mitochondria modulates organic acid and reactive oxygen species production in nickel hyperaccumulator Alyssum murale. J Biol Chem 288:7351-7362

Assunção AGL, Da Costa Martins P, De Folter S, Vooijs R, Schat H, Aarts MGM (2001) Elevated expression of metal transporter genes in three accessions of the metal hyperaccumulator Thlaspi caerulescens. Plant Cell Environ 24:221-226

Assunção AGL, Bleeker P, ten Bookum WM, Vooijs R, Schat H (2008) Intraspecific variation of metal preference patterns for hyperaccumulation in Thlaspi caerulescens: evidence from binary metal exposures. Plant Soil 303:289-299

Becher M, Talke IN, Krall L, Krämer U (2004) Cross-species microarray transcript profiling reveals high constitutive expression of metal homeostasis genes in shoots of zinc hyperaccumulator Arabidopsis halleri. Plant J 37:251-268

Bert V, Bonnin I, Saumitou-laprade P, de Laguérie P, Petit D (2002) Do Arabidopsis halleri from nonmetallicolous populations accumulate zinc and cadmium more effectively than those from metallicolous populations? New Phytol 155:47-57

Besnard G, Basic N, Christin P-A, Savova-Bianchi D, Galland N (2009) Thlaspi caerulescens (Brassicaceae) population genetics in western Switzerland: is the genetic structure affected by natural variation of soil heavy metal concentrations? New Phytol 181:974-984

Bhatia NP, Baker AJM, Walsh KB, Midmore DJ (2005) A role for nickel in osmotic adjustment in drought-stressed plants of the nickel hyperaccumulator Stackhousia tryonii Bailey. Planta 223:134-139 
Boyd RS (2009) High-nickel insects and nickel hyperaccumulator plants: a review. Insect Sci 16:19-31

Boyd RS (2012) Plant defense using toxic inorganic ions: conceptual models of the defensive enhancement and joint effects hypotheses. Plant Sci 195:88-95

Boyd RS, Martens SN (1992) The raison d'être for metal for metal hyperaccumulation by plants. In: Baker AJM, Proctor J, Reeves RD (eds) The vegetation of ultramafic (Serpentine) soils. Intercept, Andover, pp 279-289

Boyd RS, Martens SN (1998) Nickel hyperaccumulation by Thlaspi montanum var. montanum (Brassiaceae): a constitutive trait. Am J Bot 85:259-265

Boyd RS, Moar WJ (1999) The defensive function of Ni in plants: response of the polyphagous herbivore Spodoptera exigua (Lepidoptera: Noctuidae) to hyperaccumulator and accumulator species of Streptanthus (Brassicaceae). Oecologia 118: 218-224

Boyd RS, Shaw JJ, Martens SN (1994) Nickel hyperaccumulation defends Streptanthus polygaloides (Brassicaceae) against pathogens. Am J Bot 81:294-300

Brown TA, Shrift A (1981) Exclusion of selenium from proteins of selenium-tolerant Astragalus species. Plant Physiol 67:1051-1053

Cabannes E, Buchner P, Broadley MR, Hawkesford MJ (2011) A comparison of sulfate and selenium accumulation in relation to the expression of sulfate transporter genes in Astragalus species. Plant Physiol 157:2227-2239

Cecchi L, Gabbrielli R, Arnetoli M et al (2010) Evolutionary lineages of nickel hyperaccumulation and systematics in European Alysseae (Brassicaceae): evidence from nrDNA sequence data. Ann Bot 106:751-767

Craciun Ar, Meyer C-L, Chen J, Roosens N, De Groodt R, Hilson P, Verbruggen $\mathrm{N}$ (2012) Variation in HMA4 copy number and expression among Noccaea caerulescens populations presenting different levels of $\mathrm{Cd}$ tolerance and accumulation. J Exp Bot 63:4179-4189

Deinlein U, Weber M, Schmidt H, Rensch S, Trampczynska A, Hansen TH, Husted S, Schjoerring JK, Talke IN, Krämer U, Clemens S (2012) Elevated nicotianamine levels in Arabidopsis halleri roots play a key role in zinc hyperaccumulation. Plant Cell 24:708-723

El Mehdawi AF, Quinn CF, Pilon-Smits EAH (2011a) Effects of selenium hyperaccumulation on plant-plant interactions: evidence for elemental allelopathy. New Phytol 191:120-131

El Mehdawi AF, Quinn CF, Pilon-Smits EAH (2011b) Selenium hyperaccumulators facilitate selenium-tolerant neighbors via phytoenrichment and reduced herbivory. Curr Biol 21:1440-1449

El Mehdawi AF, Cappa JJ, Fakra SC, Self J, Pilon-Smits EAH (2012) Interactions of selenium hyperaccumulators and nonaccumulators during cocultivation on seleniferous or nonseleniferous soil-the importance of having good neighbors. New Phytol 194:264-277

El-Mehdawi AF, Pilon-Smits EAH (2012) Ecological aspects of plant selenium hyperaccumulation. Plant Biol 14:1-10

Feist LJ, Parker DR (2001) Ecotypic variation in selenium accumulation among populations of Stanleya pinnata. New Phytol 149:61-69

Freeman JL, Bañuelos GS (2011) Selection of salt and boron tolerant selenium hyperaccumulator Stanleya pinnata genotypes and characterization of Se phytoremediation from agricultural drainage sediments. Environ Sci Tech 45:9703-9710

Freeman JL, Persans MW, Nieman K, Albrecht C, Peer W, Pickering IJ, Salt DE (2004) Increased glutathione biosynthesis plays a role in nickel tolerance in Thlaspi nickel hyperaccumulators. Plant Cell 16:2176-2191

Freeman JL, Zhang LH, Marcus MA, Fakra S, Pilon-Smits EAH (2006) Spatial imaging, speciation and quantification of selenium in the hyperaccumulator plants Astragalus bisulcatus and Stanleya pinnata. Plant Physiol 142:124-134

Freeman JL, Lindblom SD, Quinn CF, Fakra S, Marcus MA, PilonSmits EAH (2007) Selenium accumulation protects plants from herbivory by Orthoptera via toxicity and deterrence. New Phytol 175:490-500

Freeman JL, Quinn CF, Lindblom SD, Klamper EM, Pilon-Smits EAH (2009) Selenium protects the hyperaccumulator Stanleya pinnata against black-tailed prairie dog herbivory in native seleniferous habitats. Am J Bot 96:1075-1085

Freeman JL, Tamaoki M, Stushnoff C, Quinn CF, Cappa JJ, Devonshire J, Fakra SF, Marcus MA, McGrath SP, Van Hoewyk D, Pilon-Smits EAH (2010) Molecular mechanisms of selenium tolerance and hyperaccumulation in Stanleya pinnata. Plant Physiol 153:1630-1652

Freeman JL, Marcus MA, Fakra SC, Devonshire J, McGrath SP, Pilon-Smits EAH (2012) Seeds of selenium hyperaccumulators Stanleya pinnata and Astragalus bisulcatus are colonized by Seresistant, Se-excluding wasp and beetle herbivores. PLoS ONE 7(12): 50516

Galardi F, Corrales I, Mengoni A, Pucci S, Barletti L, Barzanti R, Arnetoli M, Gabbrielli R, Gonnelli C (2007) Intra-specific differences in nickel tolerance and accumulation in the Ni-hyperaccumulator Alyssum bertolonii. Environ Exp Bot 60:377-384

Gao L, Peng K, Xia Y, Wang G, Niu L, Lian C, Shen Z (2013) Cadmium and manganese accumulation in Phytolacca americana L. and the roles of non-protein thiols and organic acids. Int J Phytoremed 15:307-319

Hanikenne M, Talke IN, Haydon MJ, Lanz C, Nolte A, Motte P, Kroymann J, Weigel D, Krämer U (2008) Evolution of metal hyperaccumulation required cis-regulatory changes and triplication of HMA4. Nature 453:391-395

Hanson B, Lindblom SD, Loeffler ML, Pilon-Smits EAH (2004) Selenium protects plants from phloem-feeding aphids due to both deterrence and toxicity. New Phytol 162:655-662

Jhee EM, Dandridge KL, Christy AM Jr, Pollard AJ (1999) Selective herbivory on low-zinc phenotypes of the hyperaccumulator Thlaspi caerulescens (Brassiaceae). Chemoecology 9:93-95

Krämer U (2010) Metal hyperaccumulation in plants. Annu Rev Plant Biol 61:517-534

Krämer U, Cotter-Howells JD, Charnock JM, Baker AJM, Smith JAC (1996) Free histidine as a metal chelator in plants that accumulate nickel. Nature 379:635-638

Krämer U, Pickering IJ, Prince RC, Raskin I, Salt DE (2000) Subcellular localization and speciation of nickel in hyperaccumulator and non-accumulator Thlaspi species. Plant Physiol 122:1343-1353

Lin YF, Liang HM, Yang SY, Boch A, Clemens S, Chen CC, Wu JF, Huang JL, Yeh KC (2009) Arabidopsis IRT3 is a zinc-regulated and plasma membrane localized zinc/iron transporter. New Phytol 182:392-404

Lombi E, Zhao F, Dunham S, Mcgrath SP (2000) Cadmium accumulation in populations of Thlaspi caerulescens and Thlaspi goesingense. New Phytol 145:11-20

Lu L, Tian S, Yang X, Wang X, Brown P, Li T, He Z (2008) Enhanced root-to-shoot translocation of cadmium in the hyperaccumulating ecotype of Sedum alfredii. J Exp Bot 59:3203-3213

Lu L, Tian S, Zhang J, Yang X, Labavitch JM, Webb SM, Latimer M, Brown PH (2013) Efficient xylem transport and phloem remobilization of $\mathrm{Zn}$ in the hyperaccumulator plant species Sedum alfredii. New Phytol 198:721-731

Ma LQ, Komar KM, Tu C, Zhang W, Cai Y, Kennelley ED (2001) A fern that hyperaccumulates arsenic. Nature 409:579

Maestri E, Marmiroli M, Visioli G, Marmiroli N (2010) Metal tolerance and hyperaccumulation: costs and trade-offs between traits and environment. Environ Exp Bot 68:1-13 
Martens SN, Boyd RS (2002) The defensive role of Ni hyperaccumulation by plants: a field experiment. Am J Bot 89:998-1003

Mathews S, Ma LQ, Rathinasabapathi B, Stamps RH (2009) Arsenic reduced scale-insect infestation on arsenic hyperaccumulator Pteris vittata L. Environ Exp Bot 65:282-286

Meyer CL, Peisker D, Courbot M, Craciun AR, Cazalé AC, Desgain $\mathrm{D}$, Schat H, Clemens S, Verbruggen N (2011) Isolation and characterization of Arabidopsis halleri and Thlaspi caerulescens phytochelatin synthases. Planta 234:83-95

Neuhierl B, Böck A (1996) On the mechanism of selenium tolerance in selenium-accumulating plants. Purification and characterization of a specific selenocysteine methyltransferase from cultured cells of Astragalus bisculatus. Eur J Biochem 239:235-238

Ó Lochlainn S, Bowen HC, Fray RG, Hammond JP, King GJ, White PJ, Graham NS, Broadley MR (2011) Tandem quadruplication of HMA4 in the zinc ( $\mathrm{Zn})$ and cadmium $(\mathrm{Cd})$ hyperaccumulator Noccaea caerulescens. PloS One 6:e17814. doi:10.1371/ journal.pone. 0017814

Ohno M, Uraji M, Shimoishi Y, Mori IC, Nakamura Y, Murata Y (2012) Mechanisms of selenium tolerance of the Arabidopsis thaliana knockout mutant of sulfate transporter Sultr 1;2. Biosci Biotechnol Biochem 76:993-998

Pollard AJ, Bakers AJM (1997) Deterrence of herbivory by zinc hyperaccumulation in Thlaspi caerulescens (Brassicaceae). New Phytol 135:655-658

Quinn CF, Freeman JL, Galeas ML, Klamper EM, Pilon-Smits EAH (2008) The role of selenium in protecting plants against prairie dog herbivory: implications for the evolution of selenium hyperaccumulation. Oecologia 155:267-275

Quinn CF, Freemam JL, Reynolds RJB, Cappa JJ, Fakra SC, Marcus MA, Lindblon SD, Quinn EK, Bennett LE, Pilon-Smits EAH (2010) Selenium hyperaccumulation offers protection from cell disruptor herbivores. BMC Ecol. http://www.biomedcentral.com /1472-6785/10/19

Quinn CF, Wyant KA, Wangeline AL, Shulman J, Galeas ML, Valdez JR, Self JR, Paschke MW, Pilon-Smits EAH (2010b) Enhanced decomposition of selenium hyperaccumulator litter in a seleniferous habitat-evidence for specialist decomposers? Plant Soil 341:51-61

Reeves RD, Baker AJM (1984) Studies on metal uptake by plants from serpentine and non-serpentine populations of Thlaspi goesingense Halacsy (Cruciferae). New Phytol 98:191-204

Reeves RD, Baker AJM (2000) Metal-accumulating plants. In: Raskin I, Ensley BD (eds) Phytoremediation of toxic metals: using plants to clean up the environment. Wiley, NewYork, pp 193-229

Richau KH, Kozhevnikova AD, Seregin IV, Vooijs R, Koevoets PLM, Smith JAC, Ivanov VB, Schat H (2009) Chelation by histidine inhibits the vacuolar sequestration of nickel in roots of the hyperaccumulator Thlaspi caerulescens. New Phytol 183:106-116

Roosens N, Verbruggen N, Meerts P, Ximénez-Embún P, Smith JAC (2003) Natural variation in cadmium tolerance and its relationship to metal hyperaccumulation for seven populations of Thlaspi caerulescens from western Europe. Plant, Cell Environ 26:1657-1672

Schneider T, Persson DP, Husted S, Schellenberg M, Gehrig P, Lee Y, Martinoia E, Jan K. Schjoerring JK, Meyer S (2013) A proteomics approach to investigate the process of $\mathrm{Zn}$ hyperaccumulation in Noccaea caerulescens (J \& C. Presl) F.K. Meyer. Plant J 73:131-142

Shibagaki N, Rose A, McDermott JP, Fujiwara T, Hayashi H, Yoneyama T, Davies JP (2002) Selenate-resistant mutants of
Arabidopsis thaliana identify Sultr1;2, a sulfate transporter required for efficient transport of sulfate into roots. Plant J 29:485-486

Shrift AV, Virupaksha TK (1965) Seleno-amino acids in seleniumaccumulating plants. Biochim Biophys Acta 100:65-75

Sors TG, Ellis DR, Na GN, Lahner B, Lee S, Leustek T, Pickering IJ, Salt DE (2005) Analysis of sulfur and selenium assimilation in Astragalus plants with varying capacities to accumulate selenium. Plant J 42:785-797

Stevens PF (2001 onwards) Angiosperm Phylogeny Website. Version 12 , July 2012 (and more or less continuously updated since). http://www.mobot.org/MOBOT/research/APweb/

Tappero R (2008) Microspectroscopic study of cobalt speciation and localization in hyperaccumulator Alyssum murale. Dissertation, University of Delaware

Terry N, Zayed AM, de Souza MP, Tarun AS (2000) Selenium in higher plants. Annu Rev Plant Physiol 51:401-432

Tian S, Lu L, Labavitch J, Yang X, He Z, Hu H, Sarangi R, Newville M, Commisso J, Brown P (2011) Cellular sequestration of cadmium in the hyperaccumulator plant species Sedum alfredii. Plant Physiol 157:1914-1925

Ueno D, Milner MJ, Yamaji N, Yokosho K, Koyama E, Zambrano MC, Kaskie M, Ebbs S, Kochian LV, Ma JF (2011) Elevated expression of TcHMA3 plays a key role in the extreme Cd tolerance in a Cd-hyperaccumulating ecotype of Thlaspi caerulescens. Plant J 66:852-862

Valdez-Barillas JR, Quinn CF, Freeman JL, Lindblom SD, Fakra S, Marcus MA, Gilligan TM, Alford ER, Wangeline AL, PilonSmits EAH (2012) Selenium distribution and speciation in the hyperaccumulator Astragalus bisulcatus and associated ecological partners. Plant Physiol 159:1834-1844

Van der Ent A, Baker AJM, Reeves RD, Pollard AJ, Schat H (2013) Hyperaccumulators of metal and metalloid trace elements: facts and fiction. Plant Soil 362:319-334

Vickerman D, Trumble J (1999) Feeding preferences of Spodoptera exigua in response to form and concentration of selenium. Arch Insect Biochem 42:64-73

Virupaksha TK, Shrift A (1965) Biochemical differences between selenium accumulator and non-accumulator Astragalus species. Biochim Biophys Acta 107:69-80

Weber M, Harada E, Vess C, von Roepenack-Lahaye E, Clemens S (2004) Comparative microarray analysis of Arabidopsis thaliana and Arabidopsis halleri root identifies nicotinamine synthase, a ZIP transporter and other genes as potential metal hyperaccumulation factors. Plant J 37:269-281

Whiting SN, Neumann PM, Baker AJM (2003) Nickel and zinc hyperaccumulation by Alyssum murale and Thlaspi caerulescens (Brassicaceae) do not enhance survival and whole-plant growth under drought stress. Plant, Cell Environ 26:351-360

Yao X, Chu J, Liang L, Geng W, Li J, Hou G (2012) Selenium improves recovery of wheat seedlings at rewatering after drought stress. Russ J Plant Physiol 59:701-707

Zhang L, Angle JS, Chaney RL (2007) Do high-nickel leaves shed by the nickel hyperaccumulator Alyssum murale inhibit seed germination of competing plants? New Phytol 173:509-516

Zhao FJ, Ma JF, Meharg AA, McGrath SP (2009) Arsenic uptake and metabolism in plants. New Phytol 181:777-794

Zhao L, Sun YL, Cui SX, Chen M, Yang HM, Liu HM, Chai TY, Huang F (2011) Cd-induced changes in leaf proteome of the hyperaccumulator plant Phytolacca americana. Chemosphere 85:56-66 